\title{
A new species of Argiope (Araneae: Araneidae) from Brazil
}

\author{
Paulo César Motta ${ }^{1} \&$ Herbert W. Levi ${ }^{2}$
}

\begin{abstract}
${ }^{1}$ Departamento de Zoologia, Universidade de Brasília. 70910-900 Brasília, Distrito Federal, Brasil. E-mail: mottapc@unb.br
${ }^{2}$ Museum of Comparative Zoology, Harvard University. Cambridge, MA 02138-2902, USA. E-mail: levi@fas.harvard.edu
\end{abstract}

\begin{abstract}
A new species of Argiope Audouin, 1826 is described. This is a large Argiope from South America and is found mainly in "cerrado" vegetation in central Brazil. Argiope legionis sp. nov. is most similar to A. ericae Levi, 2004 but differs from this species by the coloration and epigynum in the female and the median apophysis and embolus of the palpus in the male palp.
\end{abstract}

KEY WORDS. Arachnida; Cerrado; Neotropical; spiders; taxonomy.

Argiope Audouin is one of the most studied orb-weavers. There are 76 species in the world and only seven species in the America, including the cosmopolitan A. trifasciata (Forskål, 1775) (Levi 2004, Platnick 2009). The American Argiope are large (total length of 6-21 mm) with colored body and contrasting leg rings. The web is conspicuous, usually showing stabilimentum web decorations (Foelix 1996).

Although American Argiope has only recently been revised (Levi 2004), we describe here a new species. Argiope sp. nov. is similar to Argiope ericae Levi, 2004. Argiope ericae occurs in North of Argentina to Southern Brazil and the city of São Roque $\left(23^{\circ} 31^{\prime} \mathrm{S}, 47^{\circ} 08^{\prime} \mathrm{W}\right.$, State of São Paulo) which corresponds to the northern limit for this taxon. Argiope legionis sp. nov. is found in cerrado vegetation in the central Brazil.

The methods used are the same as those used in LevI (1993). Acronyms of the institutions: (DZUB) Departamento de Zoologia, Universidade de Brasília, Brazil; (IBSP) Instituto Butantan, São Paulo, Brazil; (MCZ) Museum of Comparative Zoology, Cambridge, Massachusetts, U.S.A.

All measurements are in millimeters. Abbreviations used are: (ALE) anterior lateral eyes; (AME) anterior median eyes; (PLE) posterior lateral eyes; (PME) posterior median eyes.

\section{TAXONOMY}

\section{Argiope legionis sp. nov. \\ Figs 1-10}

Holotype. Female holotype from Fazenda Água Limpa (155'6"S, 4756'36”W), Brasília, Distrito Federal, 5.V.2007, Brazil, P.C. Motta leg., deposited in IBSP 87388.

Paratypes. BRAziL, Distrito Federal: Brasília (Fazenda Água Limpa), 5.V.2007, P.C. Motta leg.; 4 females, 1 male (MCZ); 2 females (IBSP 87389); 1 male (IBSP 87390); 1 female (DZUB 4731).

Diagnosis. The female differs from $A$. ericae by the coloration. The abdomen of $A$. ericae has dorsal, transverse bands
(LevI 2004, fig. 68) whereas that of A. legionis is dorsally light yellow with black on the anterior of lateral tubercles (Fig. 1). The epigynum ff $A$. legionis has two folds on the anterior margin of the depressions (Figs 3-4) and in posterior view has dimples more ventral (Figs 5-6), whereas A. ericae has only one fold (LeVI 2004: fig. 64) and in posterior view has dimples dorsal (Levi 2004: fig. 65). The male (Figs 7-10) differs by having the distal end of the median apophysis of the palpus at right angle to the main axis (Fig. 9), and the tip of the conductor has a wider sclerotized area (in ventral view, Fig. 10) and the embolus tip not visible (Fig. 10).

Description. Female (Paratype, MCZ). Prosoma with appressed silver setae, except eye region black; endites, labium, sternum white with pairs of dark patches; legs with distinct wide black rings on brown. Abdomen dorsum light yellow in life, white in alcohol with a median black patch on the anterior margin, lateral tubercles with an anterior black patch (Fig. 1); venter black with paired, yellowish white spots and streaks (Fig. 2). PME about 1.0 diameter of AME; ALE 0.5 diameter, PLE 1.3. AME 1.0 diameter apart. PME 2.7 diameters apart, 3.5 from PLE. Total length $18 \mathrm{~mm}$. Carapace 7.3 long, 6.8 wide in thoracic region, 3.0 wide at its anterior narrowest diameter. First femur 10.0, patella and tibia 10.4, metatarsus 10.0, tarsus 2.1. Second 10.3, third 6.2, fourth 10.0.

Male (Paratype, MCZ). Prosoma brown with some silver setae, black on each side of clypeus. Abdomen dorsum white with a median longitudinal black band (Fig. 7); venter black with a pair of distinct, wide, white bands. Sternum with median longitudinal white band, sides darker (Fig. 8). Legs ringed light and dark brown. PME about 0.9 diameter of AME; ALE 0.7 diameter, PLE 1.2. AME 1.0 diameter apart, 1.2 from laterals. PME 2.0 diameters apart, 2.2 from PLE. Total length 5.0 $\mathrm{mm}$. Carapace $2.7 \mathrm{~mm}$ long, 2.4 wide in thoracic region, 0.8 behind posterior median eyes. First femur $2.9 \mathrm{~mm}$, patella and tibia 3.5, metatarsus 3.1, tarsus 1.2. Second patella and tibia $3.5 \mathrm{~mm}$, third 1.8 , fourth 2.7 . 

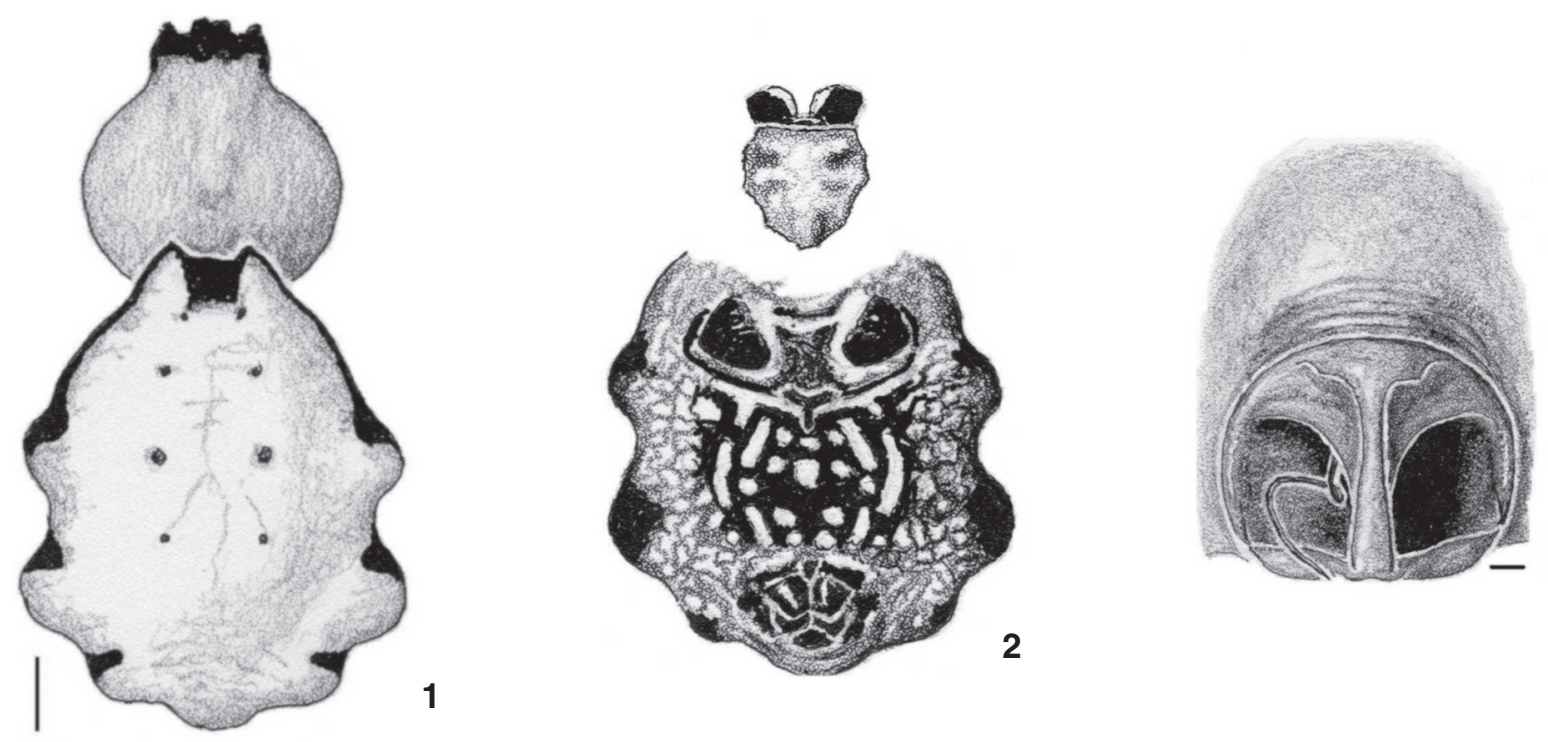

\section{3}
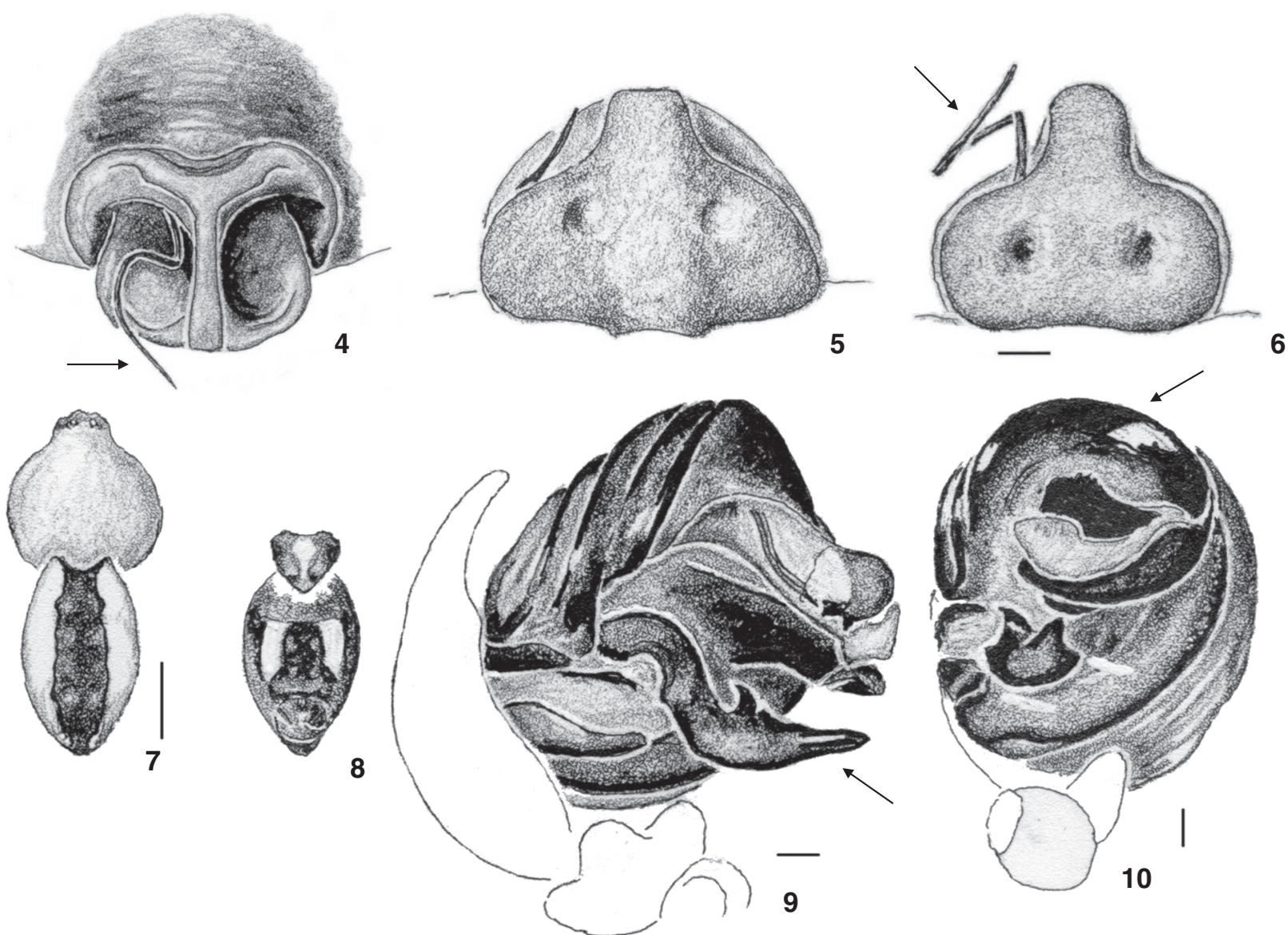

Figures 1-10. Argiope legionis sp. nov. (1-6) Female: (1) carapace and abdomen; (2) sternum and abdomen, ventral; (3-6) epigynum, arrows, male embolus: (3) ventral; (4) lateral; (5-6) posterior. (7-10) Male: (7) carapace and abdomen; (8) sternum and abdomen, ventral; (9) palpus, ventral, arrow, median apophysis; (10) palpus, mesal, arrow, conductor. Scale lines: $1.0 \mathrm{~mm}, \mathrm{genitalia:} 0.1 \mathrm{~mm}$. 
Variation. Total length of females 17.3-20.8, males 4.65.0. As in other species of Argiope, there is considerable variation of the epigynum (Figs 3-6).

Distribution. Known from two localities in Brazil: Brasília, central Brazil, and Moeda, State of Minas Gerais.

Additional material examined. Brazil, Minas Gerais, Moeda $\left(20^{\circ} \mathrm{S}, 44^{\circ} \mathrm{W}\right)$, Serra da Moeda, 1 female, 20.V.2006, E.S.S. Álvares leg. (IBSP 63232).

Natural history. The cerrado is characterized by extensive savanna formations including various types of vegetation, a mix of of woody and herbaceous plants. Adult females are very conspicuous and are found from March to June (late rainy season to early dry season) mainly in open habitats. The webs are conspicuous due to their size and the yellow appearance of the upper line of the frame thread. The vertical web is large, approximately 70 to $110 \mathrm{~cm}$ in and placed about $60-120 \mathrm{~cm}$ above ground. The stabilimentum is similar to that of other species of Brazilian Argiope, and most common is the presence of one to three lines. Sometimes kleptoparasites (Argyrodes spp.) are found in the webs. Some females examined has the male embolus stuck in the copulatory openings (Figs 3-6), suggesting it breaks during copulation. Such breakage has not been observed in other South American species of Argiope.
Etymology. The specific name honors Legião Urbana (Urban Legion), a rock band from Brasília and one of the most important musical groups from Brazil at the end of the $20^{\text {th }}$ century.

\section{ACKNOWLEDGMENTS}

To Antonio D. Brescovit (Instituto Butantan, São Paulo) for loaning material from Minas Gerais to compare.

\section{LITERATURE CITED}

FoELIX, R.E. 1996. Biology of Spiders. Oxford, Oxford University Press, Georg Thieme Verlag, $2^{\text {nd }}$ ed., 330p.

LEvI, H.W. 1993. The Neotropical orb-weaving spiders of the genera Wixia, Pozonia and Ocrepeira (Araneae: Araneidae). Bulletin of the Museum of Comparative Zoology 153: 47-141.

Levi, H.W. 2004. Comments and new records for the American genera Gea and Argiope with the description of new species (Araneae: Araneidae). Bulletin of the Museum of Comparative Zoology 158: 47-66.

Platnick, N. I. 2009. The world spider catalog, version 9.5. American Museum of Natural History, available online at: http://research.amnh.org/entomology/spiders/catalog/ index.html [Acessed: 29.I.2009]

Submitted: 13.VIII.2008; Accepted: 07.VI.2009.

Editorial responsability: Antonio D. Brescovit 